\title{
Multiple-TMD-Based Structural Vibration Control for Pumped Storage Power Plants
}

\author{
Tengfei Zhong ${ }^{1,2}$, Xin Feng ${ }^{1,2, *}$, Yu Zhang ${ }^{1,2}$ and Jing Zhou ${ }^{1,2}$ \\ 1 State Key Laboratory of Coastal and Offshore Engineering, Dalian University of Technology, \\ Dalian 116024, Liaoning, China; zhongtengfei@mail.dlut.edu.cn (T.Z.); eerd_zyu@dlut.edu.cn (Y.Z.); \\ zhouj@dlut.edu.cn (J.Z.) \\ 2 Institute of Earthquake Engineering, Faculty of Infrastructure Engineering, Dalian University of Technology, \\ Dalian 116024, Liaoning, China \\ * Correspondence: fengxin@dlut.edu.cn
}

Received: 19 June 2020; Accepted: 10 August 2020; Published: 12 August 2020

check for updates

\begin{abstract}
The high-frequency resonance in the superstructure of a pumped storage power station (PSPP) due to the generation unit can shorten the service life of the power station structure and even endanger its safety. Although tuned mass dampers (TMDs) have been proved to be effective in controlling structural vibration, their application in PSPPs is rare, as high-frequency vibration control of PSPPs has not been studied. In this paper, a TMD control method is proposed based on PSPP high-frequency vibration and various TMD control strategies, and a set of high-frequency TMD equipment is designed. Results of a series of vibration reduction tests and numerical analyses show that the new TMD device can effectively control the high-order mode of the structure, and the bandwidth of the suppression frequency is extended, which shows the robustness and control efficiency of the device.
\end{abstract}

Keywords: pumped storage power plants; tuned mass damper; vibration control; control strategies; high-frequency vibration

\section{Introduction}

Hydraulic power, as a type of renewable, clean, and efficient energy, has been well developed worldwide [1-3]. Pumped storage power plants (PSPPs) have become an important part of the energy infrastructure [4-6]. As the capacity and water head of the unit increase, the vibration of the unit becomes hazardous to the safety and reliable operation of the factory building structure [7].

The complex high-frequency pressure water pulsation generated by the turbine resonates with the high frequency of the plant structure, which can lead to abnormal vibration. For PSPPs, the rotating speed of the head and pump turbine will increase significantly, further intensifying the vibration response [8,9]. In recent years, the operation of many large hydropower units has resulted in costly downtime due to vibration problems, such as cracking of key components [10,11]. In order for a pumped storage plant to be cost-effective, the plant must have good reliability. Reliability is particularly crucial for PSPPs, because maintenance is expensive and often impossible to keep up for prolonged periods of time when regional power is available. Therefore, it is of great significance to study and overcome the vibration problem of PSPP structure for the safe operation of the unit.

It is well known that the loading from water pressure can eventually cause fatigue or failure in structures, and researchers have used numerical simulation and analysis to study the load characteristics and have suggested various vibration reduction strategies. By establishing a substructure model of the Yantan hydropower plant, Li conducted a dynamic response analysis of the structure of the hydraulic vibration of the unit and proposed decreasing the vibrational response to the structural 
floor by adding cross beams, additional steel plates, and reinforced rib beams [12]. Ma et al. proposed improving the integrity of the plant by strengthening the rigid connection between the upstream and downstream columns and implementing other measures to improve the plant strength and decrease the structural vibration in the initial stage of hydropower station structural design [13]. Scholars have proposed decreasing the pulsating pressure by supplementing the runner chamber or the draft tube with air to decrease the structural vibration [14]. Although progress was made on the vibration control of hydropower station structures in the above research, theoretical research has various limitations. First, if local strengthening of reinforced concrete structures is used as a strategy for vibration risk mitigation at the regional scale, the local vibration characteristics of the structure can be changed. However, for vibration of the plant structure that is caused by the complicated high-frequency pressure pulsation in the unit, the effect of local structural reinforcement is highly limited, and unnecessary economic losses due to the long construction period affect the normal operation of the hydropower station. Second, design optimization at the beginning of the design process is only applicable to new plant structures and not to existing plants. An optimized design can avoid the low-order mode of the structure in the resonance region; however, it cannot guarantee that the structural components will avoid the high-frequency resonance region. Finally, although the air admission method reduces the vibration of the unit, shortcomings such as high noise, high power consumption, difficult layout, and unfavorable economics remain, and the method does not fundamentally prevent the structure from resonating, hence the objective of suppressing the vibration of the superstructure is not realized. The above theoretical research is highly meaningful; however, the vibration problem of the plant structure remains and cannot be well solved for existing plants. An alternative approach to reduce the loads is structural control, which affects the response of the structure itself, and is the focus of this paper. The control of civil engineering structures has been an active research area for recent years, with the goal of protecting structures from dynamic loading due to earthquakes, wind, and other sources [15-17]. There are three major categories of control methods for structures: passive, semi-active, and active [18]. Passive structural control techniques are the most straightforward, with no energy input and constant parameters, and are the focus of this paper.

In passive vibration control, the tuned mass damper (TMD) is a popular structural control device [19]. It provides precise tuning control, especially for structures with a single frequency. The effective use of TMDs for vibration response control of structures subjected to earthquake and wind excitations was shown by Kwok and Samali [20] and Pinkaew et al. [21]. The multiple tuned mass damper (MTMD) was demonstrated to be more effective than the single tuned mass damper (STMD) in the dynamic response control of structures [22]. Improved structural vibration control was demonstrated by using the damper with optimal parameter values. Villaverde induced random and sinusoidal excitation on a wooden three-layer TMD structure model via shaking table experiments, and the results demonstrated that TMD could effectively decrease the model response [23]. Enriquez-Zarate designed a TMD for decreasing the resonance effect of the bottom layer of the structure due to several vibrations via a theoretical and experimental comparison of vibrational responses to the three-layer structure [24], and conducted a numerical analysis and an experimental evaluation of the dynamic characteristics of the entire mechanical system and its stability. Li proposed a multi-double-tuned mass damper control strategy and demonstrated by numerical analysis that it had higher effectiveness and robustness [25]. The above research mainly used TMDs to control the structural low-frequency response caused by an earthquake or wind vibration and investigated various TMD control strategies. The vibration control problem of structures with high frequency has yet to be studied. Moreover, the research is mainly based on numerical analysis, and the performance of a physical model of TMD damping remains to be verified. Therefore, it is necessary to evaluate the control performance of TMD on high-frequency vibration via a physical model.

The key steps in reducing the high-frequency vibration of the structures of PSPPs are to design a high-frequency TMD and implement a control method for high-frequency vibration. In contrast to low-frequency control, the vibrational response of the top structure is typically the strongest, and the 
TMD can be effectively controlled by arranging it on the top of the structure. High-frequency vibration often causes higher-order modal vibration of the structure, and the maximum response does not always occur at the top of the structure, hence the damping effect of traditional control strategies is not significant. In view of the shortcomings of previous research, this investigation is the first to consider the combined effects of passive structural control and water pressure pulsation and use the modal analysis method and fixed-point theory to derive the optimal tuning relationship for a certain mode of a multiple-degree-of-freedom system. Based on the high-frequency characteristics of the superstructure of a pumped storage power plant, a vibration control method of the plant structure is proposed and a TMD device with a high-frequency tuning function is designed, then physical model tests are conducted to evaluate the damping effects of various TMD control strategies. The feasibility of the proposed method is further verified by numerical simulations, and the vibration damping performance of different control strategies is analyzed more comprehensively from the frequency domain perspective. The results demonstrate that passive TMDs can be an effective load mitigation strategy for PSPPs to reduce the structural response, which can provide guidance for further research on structural vibration control of PSPPs.

\section{Theoretical Background}

The structure of a PSPP can be regarded as a multiple-degree-of-freedom (MDOF) system, and the governing equation of the structure under external excitation is as follows:

$$
[M]\{\ddot{x}\}+[C]\{\dot{x}\}+[K]\{x\}=-[M]\{I] \ddot{x}_{g}
$$

where $[M],[C]$, and $[K]$ are the mass matrix, decoupled damping matrix, and stiffness matrix of the structure, respectively; $\{x\}$ is the displacement vector; $\{I\}$ is the load indicator vector, where the element along the vibration direction is 1 and the rest is 0 ; and $\ddot{x}_{g}$ is the ground acceleration.

For a damping structure TMD system with N DOF and a TMD placed on the $j$ th floor of the structure, the dynamic equation can be written as follows:

For a general $i$ th floor mass, assuming that the TMD is installed at a certain position of the structure, the corresponding is the $i$ th degree of freedom of the structure. When the TMD is acting, the equation of motion of the structure is:

$$
M_{i} \ddot{x}_{i}+C_{i} \dot{x}_{i}+K_{i} x_{i}-\delta_{i j}\left\{c_{t}\left(\dot{x}_{t}-\dot{x}_{i}\right)+k_{t}\left(x_{t}-x_{i}\right)\right\}=-M_{i} \ddot{x}_{g}
$$

where $\delta_{i j}=\left\{\begin{array}{ll}0 & i \neq j \\ 1 & i=j\end{array}\right.$ and the equation of motion of the TMD is:

$$
m_{t} \ddot{x}_{t}+c_{t}\left(\dot{x}_{t}-\dot{x}_{i}\right)+k_{t}\left(x_{t}-x_{i}\right)=-m_{t} \ddot{x}_{g}
$$

where $M_{i}, C_{i}$, and $K_{i}$ are the mass, damping, and stiffness of the $i$ th floor of the structure, respectively; $m_{t}, c_{t}$, and $k_{t}$ are the mass, damping, and stiffness of the TMD; $x_{t}$ is the displacement of the TMD; and $x_{i}$ is the displacement of the $i$ th floor of the structure.

For high-frequency vibration of the plant structure, the high-frequency excitation causes the $r$ th mode vibration of the structure, and the TMD is designed to be the $r$ th mode of the control structure. Assuming that the modal mass of the $r$ th-order main mode is $M_{r}$, the modal stiffness is $K_{r}$, and the modal damping is $C_{r}$, the relevant equations of motion can be written as [26]:

$$
\begin{gathered}
M_{r} \ddot{q}_{r}+C_{r} \dot{q}_{r}+K_{r} q_{r}-\phi_{r j}\left\{c_{t}\left(\dot{x}_{t}-\dot{x}_{j}\right)+k_{t}\left(x_{t}-x_{j}\right)\right\}=-\Phi_{r} M_{r} \ddot{x}_{g} \\
m_{t} \ddot{x}_{t}+c_{t}\left(\dot{x}_{t}-\dot{x}_{j}\right)+k_{t}\left(x_{t}-x_{j}\right)=-m_{t} \ddot{x}_{g}
\end{gathered}
$$


Then the design problem is essentially similar to that of designing a TMD for a single-degree-of-freedom (SDOF) structure. Relative to the SDOF structure TMD system, there are the terms $q_{r}$ and $\phi_{r j}$ in the equation. However, if the $r$ th mode shape vector of the structure is normalized with respect to its $j$ th element, which corresponds to the TMD location, $\phi_{r j}$ becomes unity and $x_{j}=\phi_{r j} q_{r}=q_{r}$. If $\phi_{r j}$ is unity, the expressions for calculating the $r$ th modal response for the MDOF structure TMD system will be exactly the same as those for responses in the SDOF structure TMD system. In this way, the vibration control of higher modes for the powerhouse structure can be simplified to the TMD design problem of the corresponding modal coordinates.

Closed-form expressions of optimum damper parameter $\gamma_{\text {opt }}$ were developed by Ormondroyd [27] and Den Hartog [28], which minimize the steady-state response of the main mass subjected to a harmonic main mass excitation. The expressions for calculating the optimum damper parameters are given as:

$$
\begin{gathered}
\gamma_{\mathrm{opt}}=\sqrt{\frac{1}{1+\mu}} \\
\zeta_{\mathrm{opt}}=\sqrt{\frac{3 \mu}{4(2+\mu)(1+\mu)}}
\end{gathered}
$$

where $\gamma_{o p t}=\omega_{t} / \omega_{r}$ denotes the optimal ratio of TMD frequency to the structure's r-order frequency; $\zeta_{\text {opt }}$ denotes the optimal TMD damping; and $\mu=m_{t} / M_{r}$ denotes the mass ratio of the TMD to the structure's r-order modal mass. Thus, we can obtain the design parameters of the TMD through the optimal frequency ratio by which the TMD can be tuned to the best effect. In the next section, we will further explain the design and control methods of the TMD.

\section{High-Frequency TMD-Based Vibration Control Methodology for PSPPs}

A tuned mass damper is typically composed of a properly tuned spring, an auxiliary mass, and damper elements, providing frequency-dependent hysteresis that increases damping in the primary structure. The mechanism of suppressing structural vibrations by attaching a TMD is to transfer the vibration energy of the structure to the TMD and dissipate the energy at the TMD [29].

Due to the high-frequency vibration characteristics of the PSPP powerhouse structure, the natural vibration frequency is higher; therefore, it is necessary to design a higher-frequency TMD device to reduce the structural vibration. The existing TMD device is mainly used for low-frequency control and the coil spring is used as the stiffness unit. However, coil springs that can be produced currently do not have enough stiffness to control the high-frequency vibration. If the number of springs is multiplied, this not only increases the need for structural space but also limits the normal production and lifespan. In addition, many tuning devices of these springs are difficult to coordinate under high-frequency vibrations, and low reliability makes it difficult to realize the desired damping effect. Therefore, a suitable TMD device should be designed for high-frequency vibration control of powerhouse structures according to the pressure pulsation characteristics of PSPPs.

Based on pressure water pulsation characteristics, high-frequency vibration of the powerhouse structure is mainly transmitted to the surrounding concrete via the volute, and subsequently through supporting members such as beams and columns to the floor [30-32]. Due to the large space that is occupied by the large generator rotor and the equipment for the structure of a hydropower station, the floor is not suitable for installing TMD devices. Combined with the propagation path of the pressure water pulsation, reducing the vibration of the floor by controlling the structural column is considered such that the vibration energy is dissipated in the transmission path. Therefore, this paper proposes a new high-frequency TMD vibration damping device that is suitable for PSPP structures. It is based on the bending stiffness of the beam and the satisfactory deformation performance of the spring steel. By absorbing the vibration energy of the dissipative structural column, the objective of vibration reduction is realized. A schematic diagram of the device is shown in Figure 1. The device 
consists of a spring plate, a counterweight plate, and a connecting plate. The spring plate is fixed at both ends to the connecting plate so that it can be fixed to the structural column through the connecting plate. The axial stiffness of the steel spring plate is much larger than its bending stiffness, hence the first axial modal frequency of the steel spring plate is much larger than the first bending modal frequency of the system. No torsional modes occur in the target frequency range. The weight plate is supported by a steel spring plate and vibrates along its lateral direction to form a tunable mass damper system.

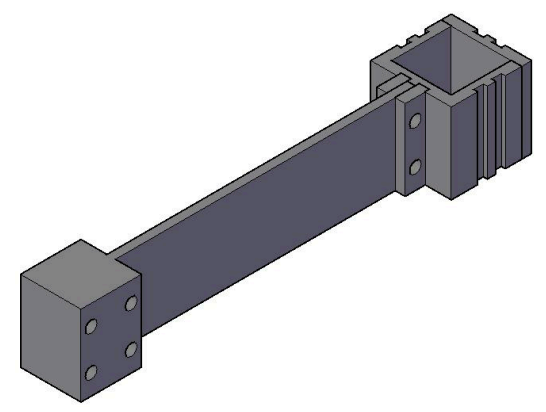

Figure 1. Concept map of the tuned mass damper (TMD) device.

To simplify the analysis, the steel plate is assumed to be made of the same material, which has cantilever length $L$, width $b$, height $h$, cross-sectional area $A$, Young's modulus $E$, density $\rho$, and quality $m_{t}$. The natural frequency of the TMD is calculated via the Rayleigh method [33].

The natural frequency $\omega_{t}$ of the TMD can be calculated as follows:

$$
\omega_{t}=\sqrt{\frac{3 E I}{m_{t} L^{3}+\frac{33}{140} \rho A L^{4}}}
$$

For the PSPP powerhouse structure, high-frequency pulsation water pressure will cause high-frequency resonance of the structure, and the structural resonance response will be readily observable. Therefore, the high frequency of the structure that is affected by the resonance is controlled using the TMD, and the mode whose structure is affected by the high-frequency vibration is considered as a subsystem to be analyzed separately; the specific technical route is shown in Figure 2 . First, the plant structure mode is identified in order to accurately obtain the modal and excitation load parameters and determine the main modal parameter information to be controlled, and the optimal multiple-degree-of-freedom structure is used to control the optimal relationship expression (Equations (6) and (7)) to further determine the TMD parameters. Then, according to the design formula of the TMD (Equation (8)), the geometric and material parameters of the TMD equipment are determined. The geometric parameters should be determined according to the size of the project's space to satisfy the space requirements as much as possible without affecting the normal operation of the hydropower station. The material parameters should be determined in coordination with the geometric parameters; it is advisable to use materials with satisfactory performance, fatigue resistance, and low cost. The TMD device is fabricated and updated using the geometric and material parameters that are specified for each condition, and whether it satisfies the design requirements is determined. If it does not satisfy the design requirements, the geometric and material parameters must be readjusted. If it does satisfy the requirements, it is installed in the controlled position of the powerhouse structure, and the vibrational response to the plant structure is measured under normal operation of the unit to evaluate the control performance of the TMD device. At the same time, the influence of different control strategies and layout positions on the damping performance is also very important. Therefore, in the following experiment and numerical simulation, the influence of different control strategies and placement on high-frequency vibration of the structure was further analyzed. 




Figure 2. High-frequency TMD vibration control method for structures of a pumped storage power plant (PSPP).

\section{Experimental Setup}

\subsection{Experimental Model}

To evaluate the performance of the TMD damping scheme, a structural model of the PSPP building was designed and fabricated and a series of tests was conducted. The experiment studied the mechanism of structure-TMD synergistic damping under high-frequency vibration and evaluated the control performance of the TMD device. Therefore, the experimental model was not limited to strict similarity in terms of the structural form and transmission path; the main objective was to investigate the damping performance of the structure-TMD system at high frequency. The experimental model can be regarded as a microreduced prototype that is similar to the upper frame structure of a PSPP. The vibrational response of the structure to high frequency was measured and the result was used to analyze the control effects of various TMD schemes. Based on the vibration reduction performance during the steel frame test, the feasibility of using TMDs to control the vibration of a hydropower station building was analyzed. In addition, the hydraulic vibration source was transmitted to the 
superstructure through the volute and the overall vibration of the structure was still excited. Therefore, the transmission path of the vibration source was not strictly simulated. Only the superstructure was studied and the overall vibrational response to the structure's high-frequency resonance was investigated. The vibration of the superstructure was mainly transmitted to the floor of the generator of the support structure. Therefore, the energy dissipation in the vibration transfer process through the control column could suppress the floor vibration. A shaking table was used as an excitation source to simulate high-frequency excitation similar to the pressure water pulsation frequency component, and the structural vibrational response was analyzed with and without TMDs. The control method of structural high-frequency vibration can be well understood through the test, which can be used as a reference for vibration control of a PSPP powerhouse structure.

In this experiment, a steel frame model was designed. The model was $0.8 \mathrm{~m}$ tall and the total mass was $57.6 \mathrm{~kg}$. The test model nodes were connected by welding. First, a finite element analysis model of the test model was established and an analysis was performed to obtain the theoretical values of the modal parameters. The analysis results demonstrate that the second-order mode of the structure in the X-direction did not differ substantially from the tail pressure water pulsation frequency that was observed in [34]; hence, the tuning frequency of the structure was determined to be the second-order mode. The first four modes of the model structure were X-direction translation, Y-direction translation, torsion, and $\mathrm{X}$-direction translational vibration. Therefore, the second-order mode was $\mathrm{X}$-direction horizontal translational vibration, and the vibration part was mainly located at the top of the first and second layer. A typical structural floor plan and test models are shown in Figure 3. The geometry and material parameters of the test model are listed in Table 1.

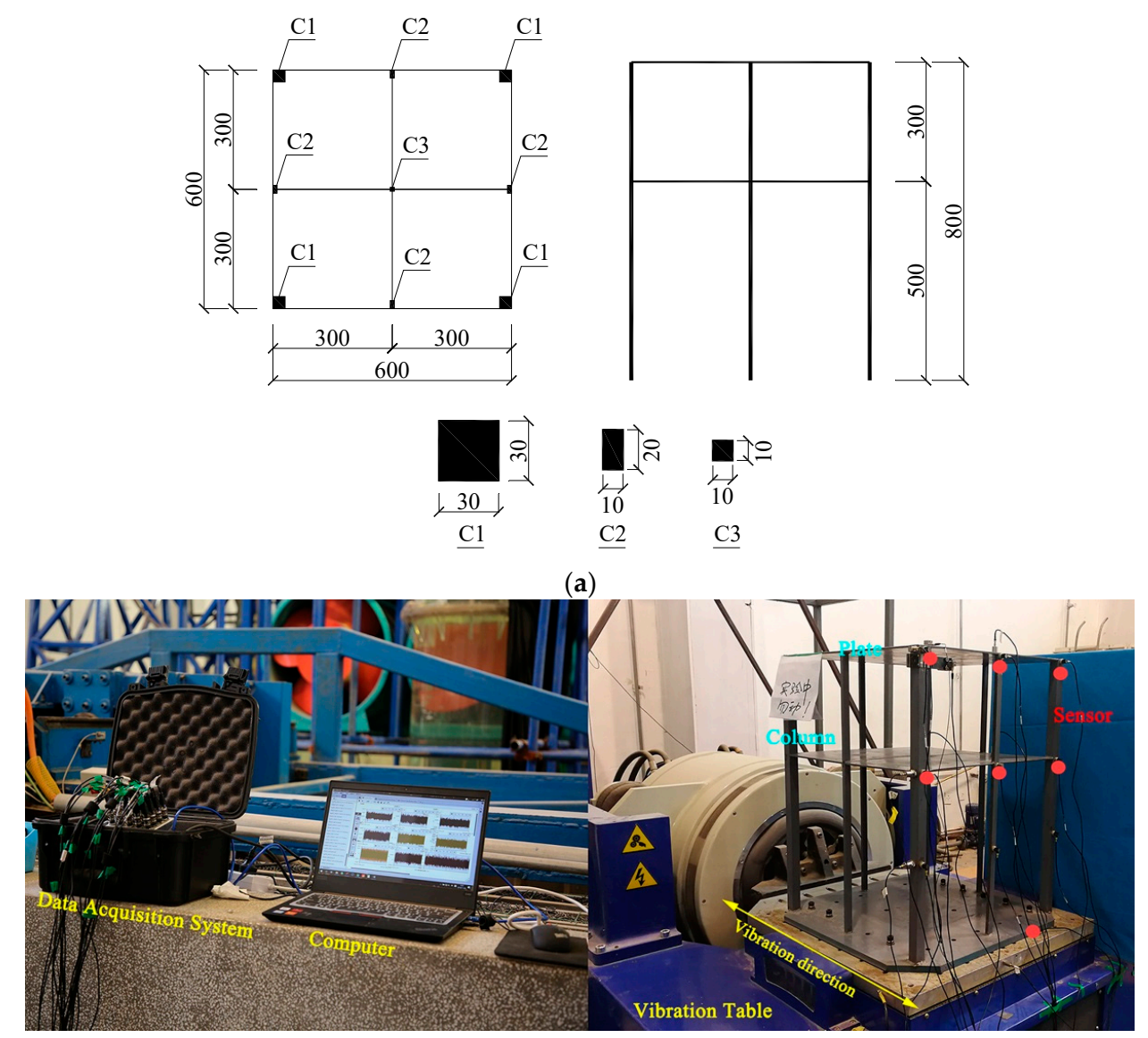

(b)

Figure 3. Test model information: (a) structural design and (b) experiment model. 
Table 1. Structural material parameters.

\begin{tabular}{cccc}
\hline Material & Modulus of Elasticity E (GPa) & Density P (Kg/M $\mathbf{3})$ & Poisson's Ratio \\
\hline steel & 200 & 7850 & 0.3 \\
\hline
\end{tabular}

\subsection{Design of the TMD}

Considering the difficulty of manufacturing and installing a TMD, a simple and practical method was adopted in the shaking table test. The installation strategy is to fix the mass on the steel spring plate to form the TMD device and fix it to the top of the structural column using a connecting damp such that the connecting fixture can realize a two-way connection. Therefore, many forms of TMD control schemes can be implemented. To study the effects of various control schemes on the damping effect of the TMD, the following schemes were adopted: single-tuned mass damper (STMD), dual-tuned mass damper (DTMD), multiple-tuned mass damper (MTMD), multiple dual-tuned mass damper (MDTMD), quadruple TMD, and spatial multi-point TMD. Among them, DTMD and MTMD are two sets of TMD forms, and MDTMD, quadruple TMD, and spatial multipoint TMD are four sets of TMD forms. The mass ratio of the TMD was $2.09 \%$, where the mass of the model $\mathrm{X}$ with respect to the second-order mode was $7.4 \mathrm{~kg}$, the corresponding TMD mass was $0.155 \mathrm{~kg}$, and the mass ratio of TMD to the total mass was $0.27 \%$. Via the addition of mass, the natural frequency of the TMD can be made close to the controlled frequency of the model structure. To further study the effects of the arrangement position on the vibration damping performance of the structure, various forms of TMDs were arranged at various positions in the structure. Figure 4 shows photographs of the arrangements of various TMD control strategies in the structure.

Based on the pressure pulsation of the unit and the high frequency at which the powerhouse structure components resonate, the test identifies the modal parameters of the model structure. Based on the numerical analysis results, the structure was subjected to a sweep analysis over $5-200 \mathrm{~Hz}$ to cover its main mode to obtain the modal parameters of the structural excitation direction. According to the analysis of modal parameters, $90-140 \mathrm{~Hz}$ was determined to be the high-frequency sweep analysis frequency band of the structure, and the high-frequency natural frequency of the structure was $111.3 \mathrm{~Hz}$.

Simple harmonics were used to simulate the vibrational response of the pressure pulsation. The load frequency was analyzed with a natural vibration frequency of $111.3 \mathrm{~Hz}$ as the excitation frequency band to analyze the structural response under a high-frequency resonance. When the various forms of TMDs were added, the simulated pressure pulsation frequency remained the same and the damping structure was excited at the same load frequency to observe the vibrational response of the structure with and without TMD. In the test, the vibration table excitation direction was defined as the $\mathrm{X}$-direction, and the vibration reduction test conditions are listed in Table 2, where suffix B indicates that the TMD device was arranged at the top of the bottom structure, suffix T indicates that the TMD device was arranged at the top of the two-layer structure, and spatial multi-point TMD indicates that four groups of TMDs are arranged on top of the two-layer structure and the bottom structure. IEPE piezoelectric acceleration sensors were used to measure the vibrational response of the structure, and were placed on top of the first and second layers to measure the acceleration response. 

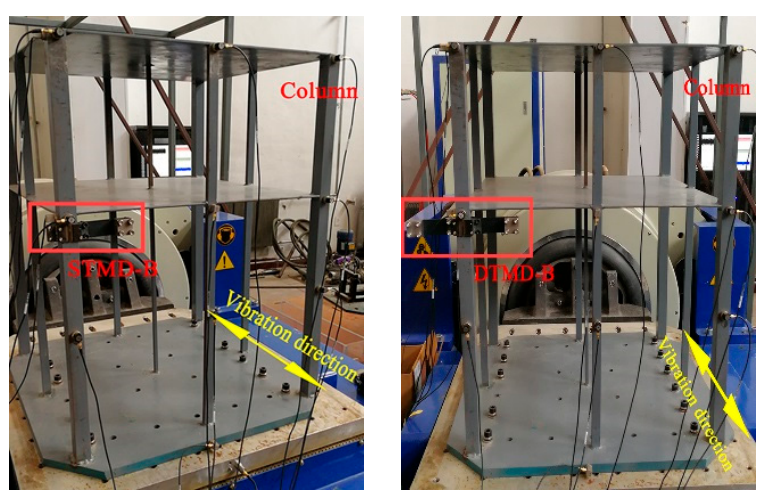

(a)
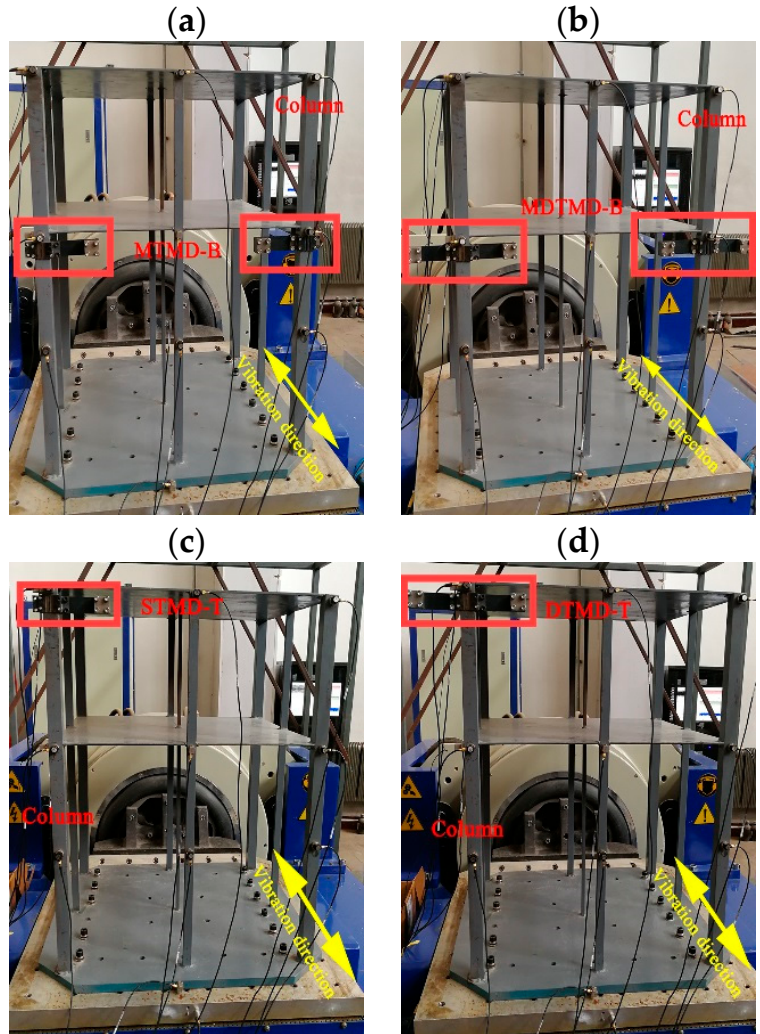

(d)

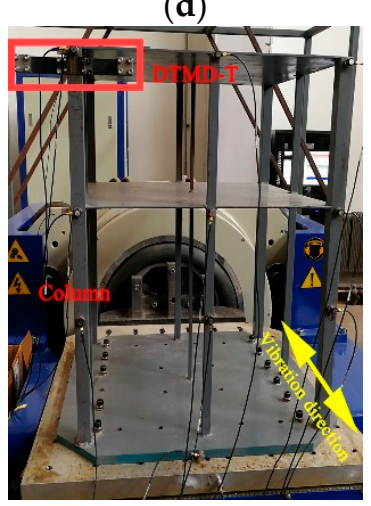

(e)

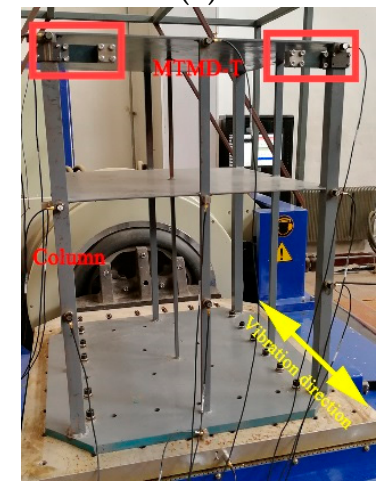

(g)

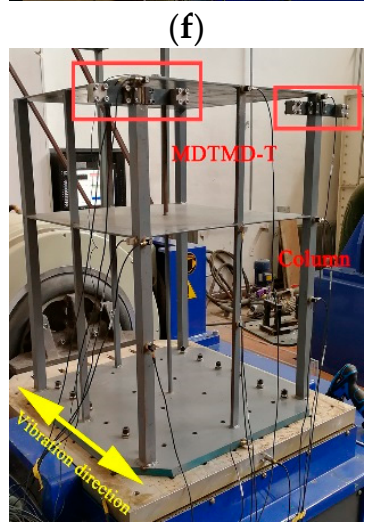

(h)

Figure 4. Cont. 


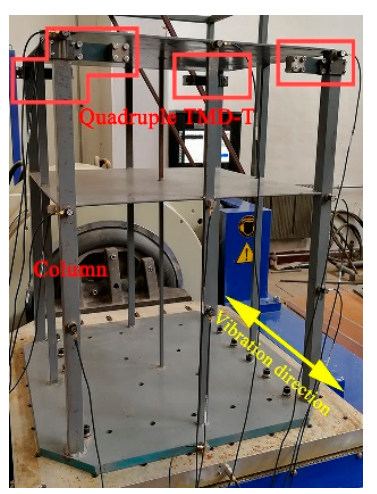

(i)

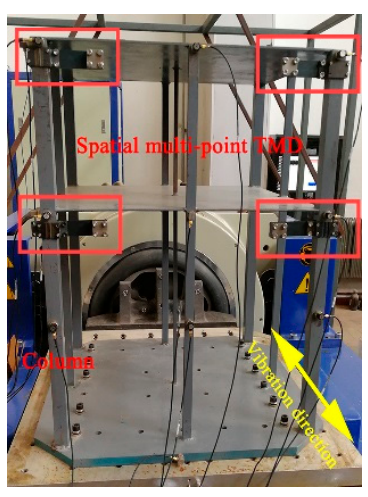

(j)

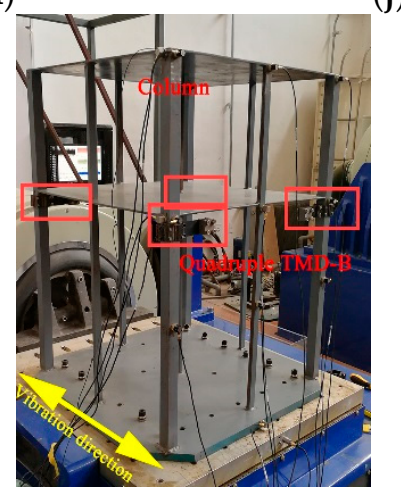

(k)

Figure 4. Forms of TMDs in the structure: (a) single-tuned mass damper (STMD)-B; (b) dual-tuned mass damper (DTMD)-B; (c) multiple-tuned mass damper (MTMD)-B; (d) multiple dual-tuned mass damper (MDTMD)-B; (e) STMD-T; (f) DTMD-T; (g) MTMD-T; (h) MDTMD-T; (i) quadruple TMD-T; (j) spatial multi-point TMD; and (k) quadruple TMD-B.

Table 2. Vibration reduction test conditions.

\begin{tabular}{clccc}
\hline Excitation Condition & Incoming Signal & $\begin{array}{c}\text { Excitation } \\
\text { Band/Hz }\end{array}$ & Amplitude/G & TMD Position \\
\hline STMD-B & Harmonic wave & 111.3 & 0.2 & Top of bottom structure \\
DTMD-B & Harmonic wave & 111.3 & 0.2 & Top of bottom structure \\
MTMD-B & Harmonic wave & 111.3 & 0.2 & Top of bottom structure \\
MDTMD-B & Harmonic wave & 111.3 & 0.2 & Top of bottom structure \\
STMD-T & Harmonic wave & 111.3 & 0.2 & Top of two-layer structure \\
DTMD-T & Harmonic wave & 111.3 & 0.2 & Top of two-layer structure \\
MTMD-T & Harmonic wave & 111.3 & 0.2 & Top of two-layer structure \\
MDTMD-T & Harmonic wave & 111.3 & 0.2 & Top of two-layer structure \\
4MTMD-T & Harmonic wave & 111.3 & 0.2 & Top of two-layer structure \\
Spatial multi-point TMD & Harmonic wave & 111.3 & 0.2 & Top and bottom of structure \\
4MTMD-B & Harmonic wave & 111.3 & 0.2 & Top of bottom structure \\
\hline
\end{tabular}

\section{Experimental Results and Analysis}

To evaluate the performance of the TMD passive control system, dampers with different control strategies were designed and implemented in the laboratory. The controlled modes of the structure were first confirmed by modal identification. Under the same harmonic load, the peak value of the measured response was obtained.

The experimental results are summarized in the following Sections 5.1 and 5.2. 


\subsection{Modal Analysis of Test Model}

The modal parameters of the structure were identified via the $5-200 \mathrm{~Hz}$ sweep excitation and the top acceleration response signal of the structure was extracted, as shown in Figure 5a. The frequency domain analysis of the top acceleration response is shown in Figure 5b, and the self-vibration frequency of the structure was obtained via the peak picking method. The high-order modal information of the structure cannot be well recognized due to the wide sweep frequency.

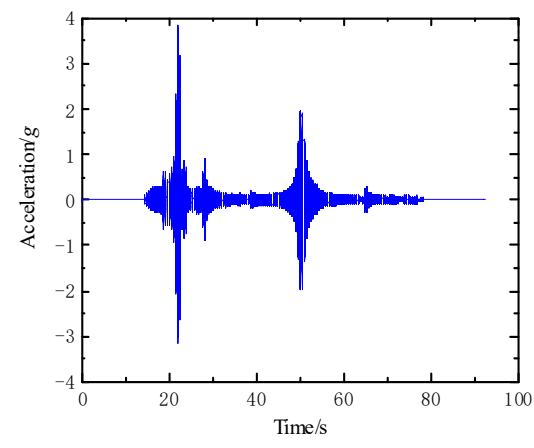

(a)

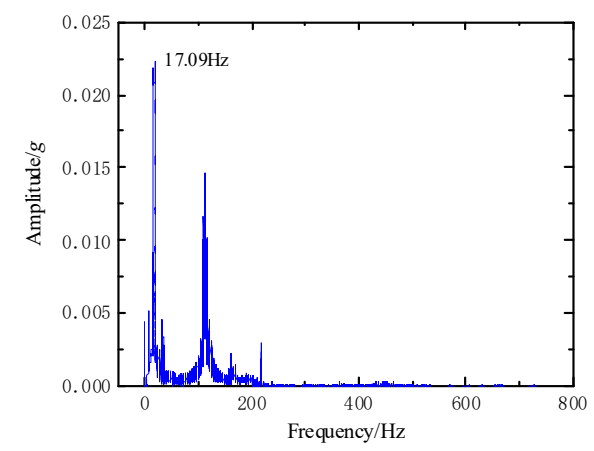

(b)

Figure 5. Modal parameter identification of structures: (a) time-history curve of acceleration and (b) frequency response curves of the structure.

To accurately obtain the second-order modal parameters of the structure, the sweep range was reduced to $90-140 \mathrm{~Hz}$. A frequency domain analysis was conducted to obtain the structure self-vibration frequency of $111.3 \mathrm{~Hz}$ (Figure 6).

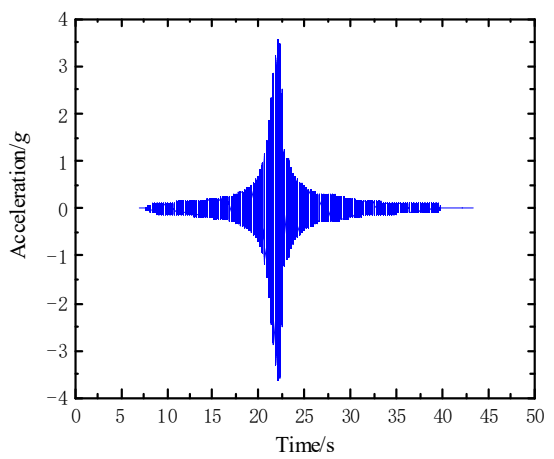

(a)

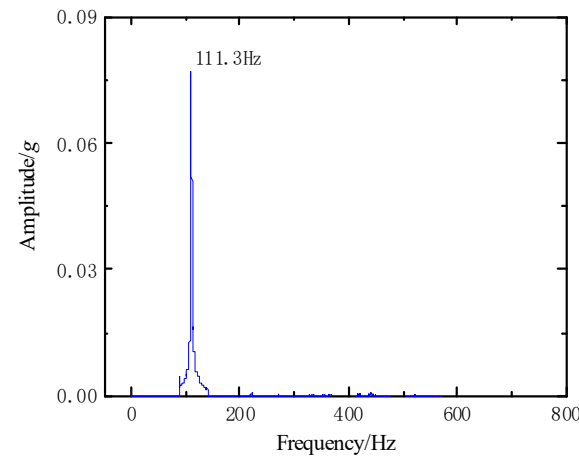

(b)

Figure 6. Parameter identification of controlled modal: (a) time-history curve of acceleration and (b) frequency response curves of the structure.

\subsection{Simple Harmonic Excitation Analysis}

According to the modal analysis results, a $111.3 \mathrm{~Hz}$ simple harmonic wave was used as the excitation frequency to apply a vibration signal to the structure to simulate pressure pulsation and structural high-frequency resonance. The peak acceleration (PA) is related to the safety of the structure, and the root mean square acceleration (RMSA) is the index of vibration energy. Therefore, to study the damping effect of the tuned mass damper, the variation of vibration energy was analyzed, and the attenuation rate of peak acceleration and root mean square acceleration were used as the evaluation indices, defined as:

$$
\begin{gathered}
A T_{P A}=\frac{P A_{O}-P A_{D}}{P A_{O}} \\
A T_{R M S A}=\frac{R M S A_{O}-R M S A_{D}}{R M S A_{O}}
\end{gathered}
$$


Here, $P A_{O}$ and $R M S A_{O}$ and $P A_{D}$ and $R M S A_{D}$ represent the peak and root mean square values of the acceleration response of the original structure and the damping structure, respectively.

Figure 7 shows the uncontrolled and controlled responses for the tested structure. The effectiveness of the proposed control strategy is clearly seen; the PA and RMSA at the top and bottom of the structure are significantly reduced compared to the uncontrolled responses. Table 3 summarizes the results of different control strategies under simple harmonic excitation tests. Taking the top layer as an example, the RMSA decay rates of STMD, DTMD, MTMD, and MDTMD are $47.56 \%, 59.08 \%, 60.24 \%$, and $77.62 \%$, respectively. A simple harmonic load is characterized by a single excitation frequency, while TMD is particularly sensitive to fixed frequency vibration. Hence, the designed TMD device reduces the structure high-frequency vibration significantly. DTMD and MTMD are the same number of design forms, and there is no substantial difference, so it can be found from the chart that the vibration reduction effect of the two is basically the same. In engineering practice, the layout scheme can be selected according to the actual situation. MDTMD had the best vibration reduction performance among the four conditions. The increase of TMD not only further improves the performance, but also the robustness of the system, which is particularly important for the occurrence of unstable excitation in practical engineering.

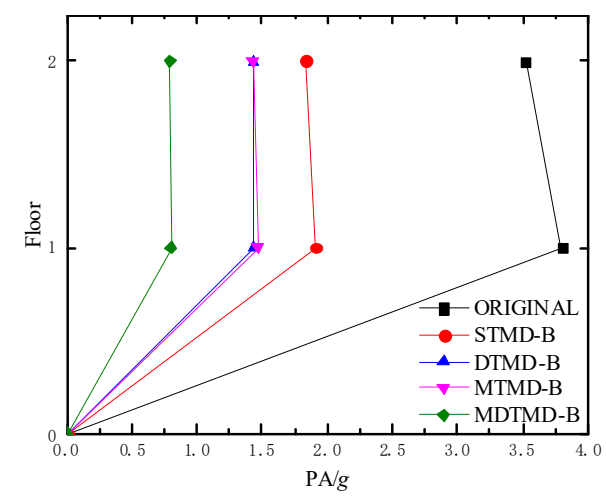

(a)

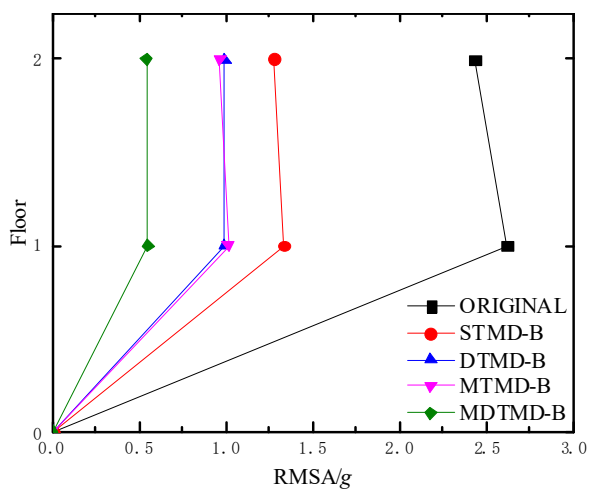

(b)

Figure 7. Structural responses of original structure and vibration-damping structure under simple harmonic excitation in various conditions: (a) peak acceleration and (b) root mean square (RMS) acceleration.

Table 3. Attenuation rates of TMD under various conditions (\%).

\begin{tabular}{ccccc}
\hline \multirow{2}{*}{ Location } & \multicolumn{2}{c}{ Top } & \multicolumn{2}{c}{ Bottom } \\
\cline { 2 - 5 } & PA & RMSA & PA & RMSA \\
\hline STMD-B & 47.87 & 47.56 & 49.62 & 48.96 \\
STMD-T & 29.95 & 31.59 & 24.35 & 25.76 \\
DTMD-B & 59.22 & 59.08 & 62.33 & 62.16 \\
DTMD-T & 44.54 & 44.22 & 36.72 & 36.14 \\
MTMD-B & 59.45 & 60.24 & 61.46 & 61.40 \\
MTMD-T & 32.43 & 34.60 & 29.34 & 29.13 \\
MDTMD-B & 77.57 & 77.62 & 79.03 & 78.88 \\
MDTMD-T & 61.21 & 61.13 & 55.68 & 54.74 \\
4MTMD-T & 62.26 & 62.16 & 63.19 & 56.15 \\
Spatial multi-point TMD & 73.00 & 73.89 & 72.93 & 73.51 \\
4MTMD-B & 77.13 & 80.73 & 73.65 & 78.02 \\
\hline
\end{tabular}

In the above four cases, TMD equipment was installed at the bottom of the structure. It can be seen from the results that the overall response of the model structure was obviously reduced. Therefore, to further study the influence of different arrangement positions on the high-frequency vibration control of the structure, the TMD devices of the four cases were arranged on the top floor 
of the structure to measure the response under simple harmonic excitation. Figure $8 \mathrm{a}-\mathrm{h}$ plots the structural acceleration response peaks and RMS values at different locations.

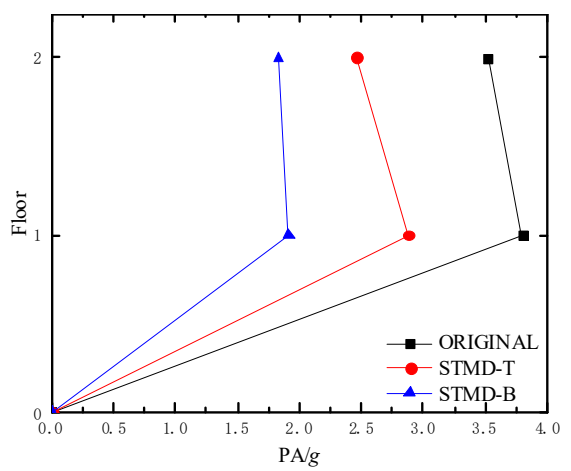

(a)



(c)



(e)

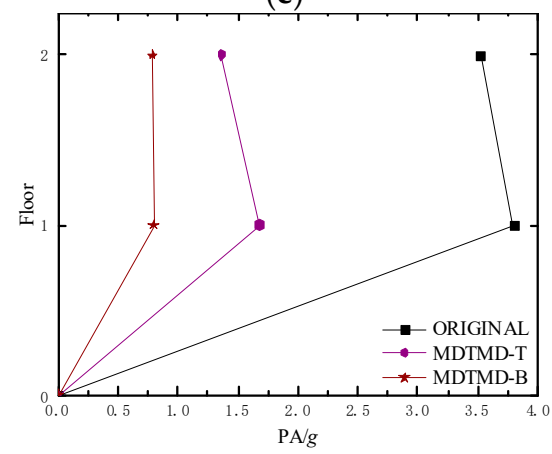

(g)

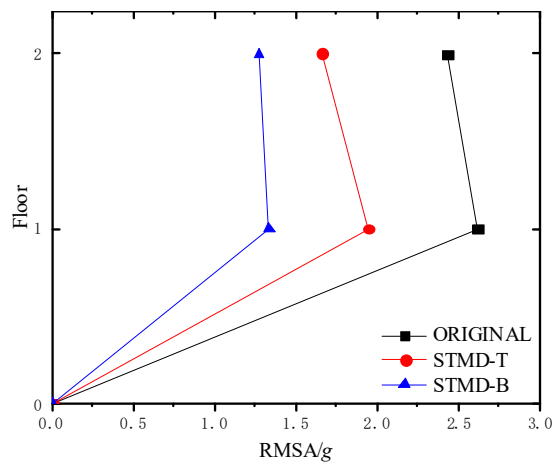

(b)

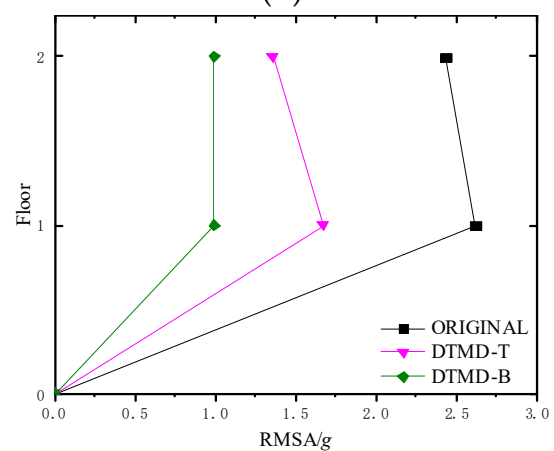

(d)

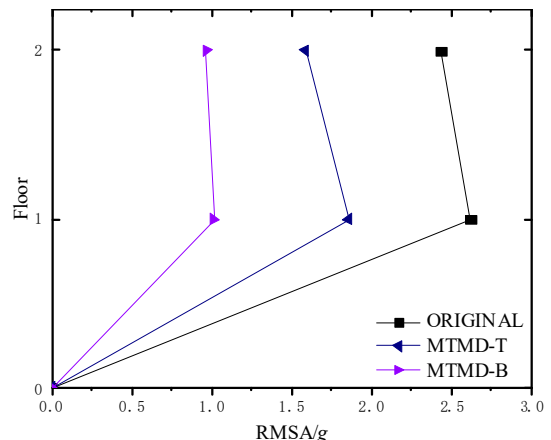

(f)

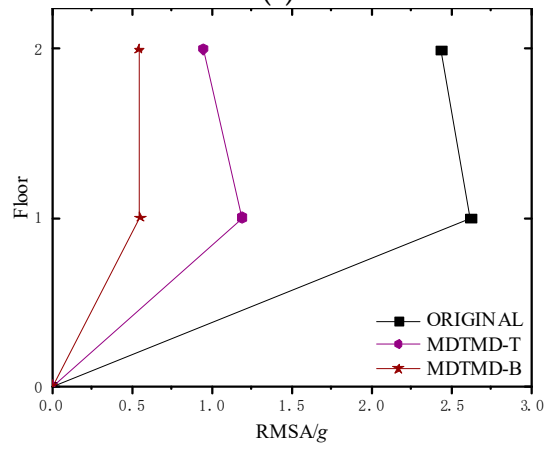

(h)

Figure 8. Structural responses of the original structure and vibration-damping structure under simple harmonic excitation various positions: (a) STMD peak acceleration; (b) STMD RMS acceleration; (c) DTMD peak acceleration; (d) DTMD RMS acceleration; (e) MTMD peak acceleration; (f) MTMD RMS acceleration; (g) MDTMD peak acceleration; and (h) MDTMD RMS acceleration. 
The results presented in Figure 8 show that the different arrangement positions of the same control strategy were different. Although the arrangement at the top of the structure can still have a certain control effect, the arrangement at the bottom of the vibration reduction effect was more obvious. The RMSA attenuation rate of the top layer increased from $31.59 \%$ to $47.56 \%$, even with the addition of a single TMD. Therefore, for high-frequency vibration control of the structure, there is an optimal arrangement, and the vibration absorption performance should be based on reasonably arranged TMDs, optimized according to the structural response under the control mode.

The vibration of the PSPP varies greatly between the various parts of the structure, and the TMD set on a single floor cannot control the complex vibration of the PSPP structure. Therefore, the operation mechanism of coordinated multi-point TMD array damping was studied by placing the TMD array system in multi-point space to optimize the vibration reduction performance. In the test, three strategies were considered: the traditional 4MTMD system was formed by arranging the STMD on four corner posts at the top and bottom of the structure, and the space multi-point TMD array system was formed by arranging the STMD on the top and bottom corner posts on the same side. The cooperative vibration reduction performance of the structure and space multi-point TMD array was tested.

As can be seen from Figure 9, the vibration control effect of the 4MTMD-B group was the best, and the RMSA attenuation rate of the top layer of the structure was $80.73 \%$. This behavior agreed with the observation in Figure 8 that the vibration response of the laid-out bottom was less than that of the laid-out top. It is due to the controller's position at the maximum controlled modal response, which absorbs the vibration response of the structure to the maximum extent and dissipates vibration energy to reduce the response of the structure. Combined with the controller groups arranged in the same layer with different vibration reduction strategies in Table 3 , the vibration reduction effects differed little. Therefore, in the actual project they can be flexibly arranged according to the site, in order to achieve the best control effect.

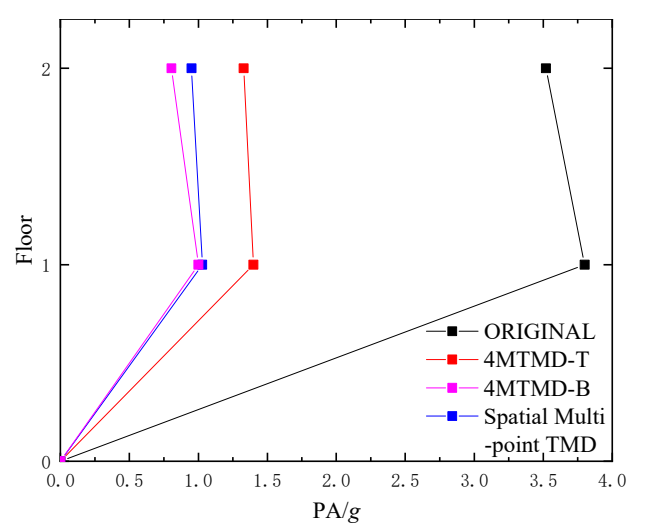

(a)

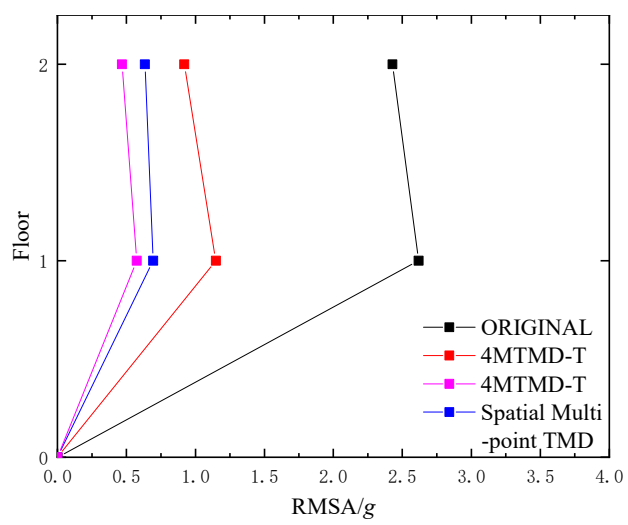

(b)

Figure 9. Structural responses of original structure and structures with various TMD control strategies under simple harmonic excitation at various positions: (a) peak acceleration and (b) RMS acceleration.

\section{Numerical Analysis of Test}

Numerical investigations were performed to further analyze the vibration damping performance of different TMD control schemes. Commercial Ansys software was adopted for the simulations. The beam element BEAM189 was used to analyze the behavior of frame columns. The shell element SHELL181 was used to model the behavior of floor. The above units have been studied in the literature [35] and the numerical results were verified by experiments. Elements combine14 and mass 21 were used to simulate TMD stiffness and mass. The finite element model is shown in Figure 10. After discretization, the finite element model had a total of 449 nodes and 252 elements. In the Ansys model, the material's geometry, density, elastic modulus, and other parameters were the same as those 
used in the test model. In this paper, only the control effect of the controller under normal use of the structure was considered, and the energy dissipation of the structure into plastic deformation was not considered. Therefore, it is assumed that the structure is in an elastic state when stimulated. The finite element method is the time integral method, which uses a fixed frequency sinusoidal wave to carry out transient analysis of the structure, in order to study the vibration absorption effect of the non-controlled and controlled structure.

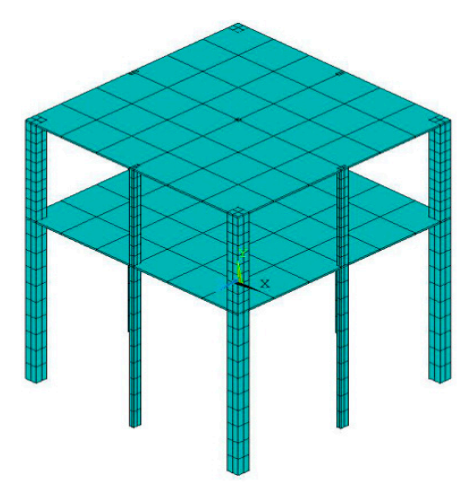

Figure 10. Finite element model.

\subsection{Parameters Affecting the Performance of TMD Installed on the Powerhouse Structure}

First, a parametric study was performed of the powerhouse structure system to investigate the effects of various control system parameters on the response control. The optimum design parameters of the TMD scheme were studied and evaluated by changing the tuning frequency ratio. Tuning frequency ratios of $0.5,0.75$, optimal, 1.25 , and 1.5 were used. The high-frequency vibration of the uncontrolled structure and the vibration damping structure were calculated. The time-history curves of displacement, velocity, and acceleration of the top and bottom layers of the structure are shown in Figure 11. It is worth noting that increasing TMD did not necessarily result in a reduced response by the structure. When the tuning frequency ratio was 0.5 and 0.75 , we found that the displacement, velocity, and acceleration response of the top layer of the structure were greater compared to the uncontrolled structure. The TMD system with these parameters not only had no good control effect, but also increased the vibration response of the structure. However, the increase in response reduction was significant up to the optimal tuning frequency ratio. It was also found that the vibration velocity of the TMD system increased as the tuning frequency ratio approached the optimum, as shown in Figure 12. Therefore, it was concluded that an optimum tuning frequency ratio exists for the TMD system. 


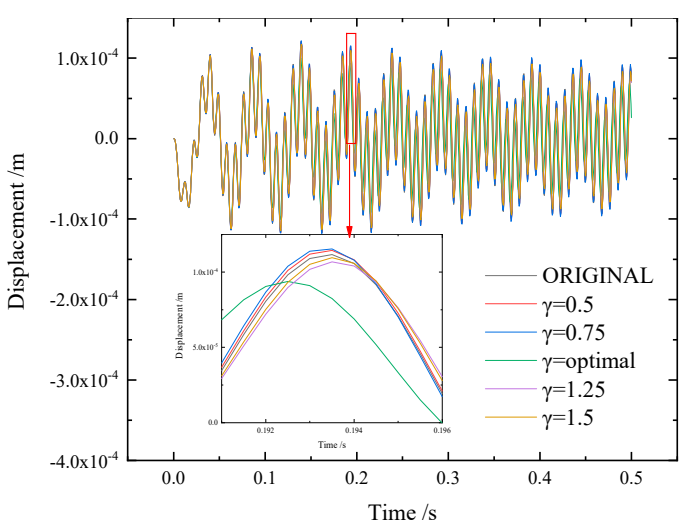

(a)

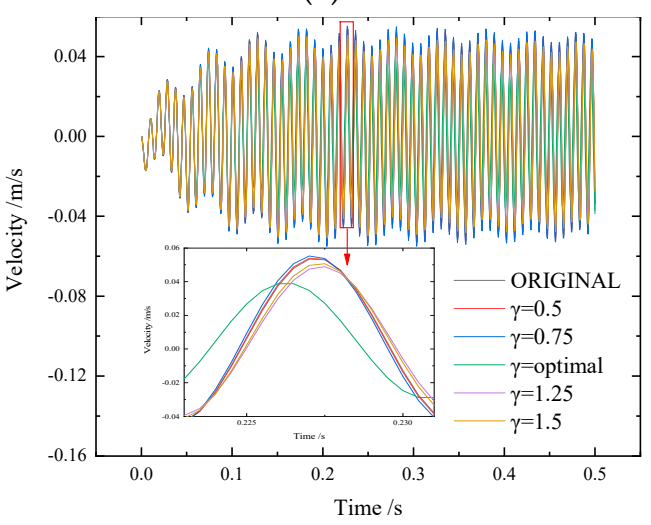

(c)

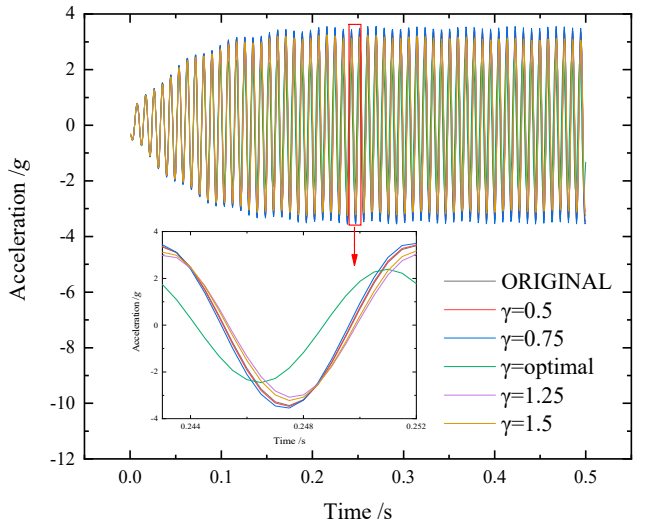

(e)

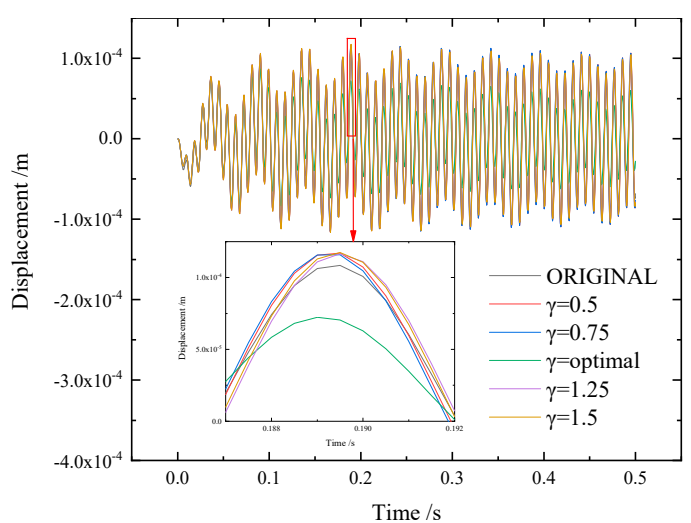

(b)

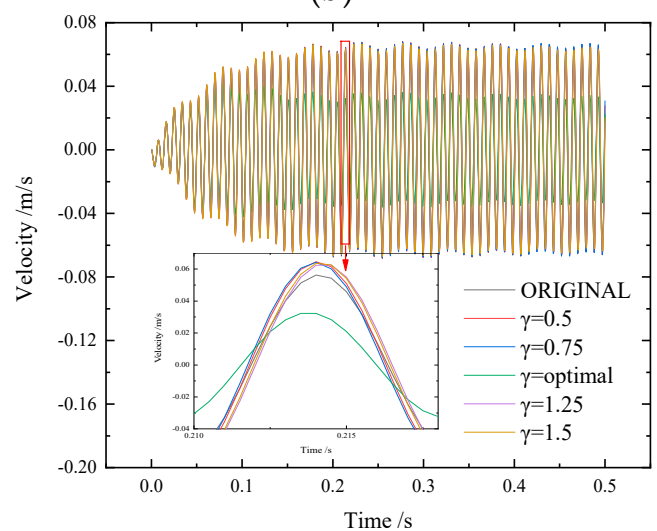

(d)

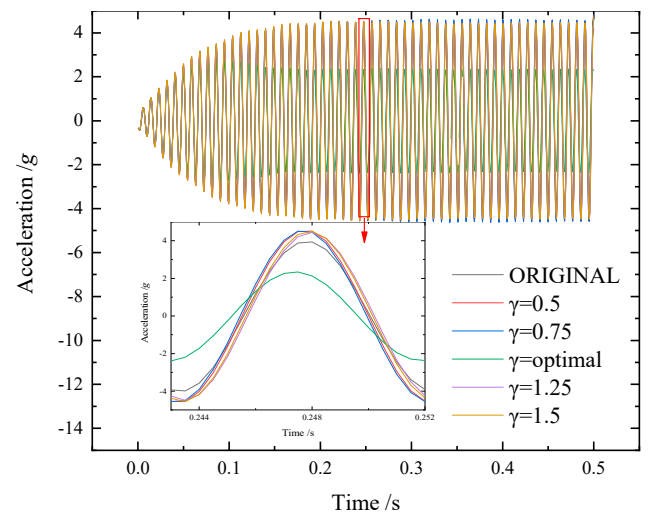

(f)

Figure 11. Comparison of time history curves at different tuning ratios: (a) displacement time history curve of the top structure; (b) displacement time history curve of the bottom structure; (c) velocity time history curve of the top structure; (d) velocity time history curve of the bottom structure; (e) acceleration time history curve of the top structure; and (f) acceleration time history curve of the bottom structure. 


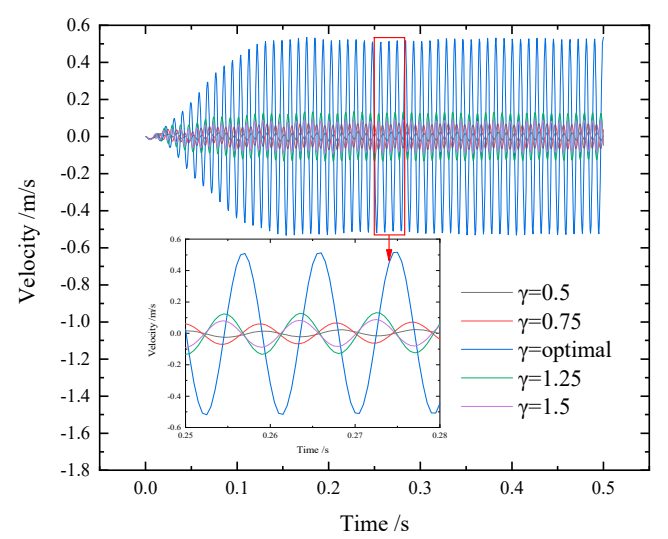

Figure 12. TMD system velocity time history curves at different tuning ratios.

Table 4 summarizes the structural responses of different tuning frequency ratios under sinusoidal excitation. It can be seen from the data that the vibration reduction effect was the most obvious when the parameters were optimal. At this point, TMD could play a better role in vibration absorption and energy dissipation.

Table 4. Structural responses with different tuning frequency ratios.

\begin{tabular}{|c|c|c|c|c|c|c|c|}
\hline \multirow{2}{*}{ Response } & \multicolumn{2}{|c|}{ Displacement $\left(10^{-4} \mathrm{~m}\right)$} & \multicolumn{3}{|c|}{ Velocity $\left(10^{-2} \mathrm{~m} / \mathrm{s}\right)$} & \multicolumn{2}{|c|}{ Acceleration (g) } \\
\hline & Top & Bottom & Top & Bottom & TMD & Top & Bottom \\
\hline Original & 1.20 & 1.08 & 5.34 & 6.00 & - & 3.47 & 4.21 \\
\hline$\gamma=0.5$ & 1.21 & 1.17 & 5.39 & 6.83 & 2.80 & 3.49 & 4.84 \\
\hline$\gamma=0.75$ & 1.21 & 1.16 & 5.52 & 6.80 & 7.12 & 3.56 & 4.83 \\
\hline$\gamma=$ optimal & 1.07 & 0.87 & 3.90 & 4.20 & 53.65 & 2.47 & 2.76 \\
\hline$\gamma=1.25$ & 1.15 & 1.17 & 4.92 & 6.57 & 13.46 & 3.12 & 4.63 \\
\hline$\gamma=1.5$ & 1.17 & 1.17 & 5.08 & 6.70 & 9.05 & 3.26 & 4.73 \\
\hline
\end{tabular}

\subsection{Time Domain Analysis of TMD Installed on the Powerhouse Structure}

In this section, the interaction mechanism of structure-TMD system and the influence law of different TMD control strategies was studied through a time domain analysis. The response of TMD and structure to high-frequency vibration is shown in Figure 13. The results show that the vibration velocity of the TMD system was much higher than that of the structure. Through further analysis, it was found that the velocity direction of the TMD was always opposite to the vibration direction of the structure, which further verified the working principle of the TMD. By observing the time history curve of the non-optimal parameter TMD in the previous section, it can be found that TMD moves in the same direction as the structure in part of the phase, thus increasing the structural response.

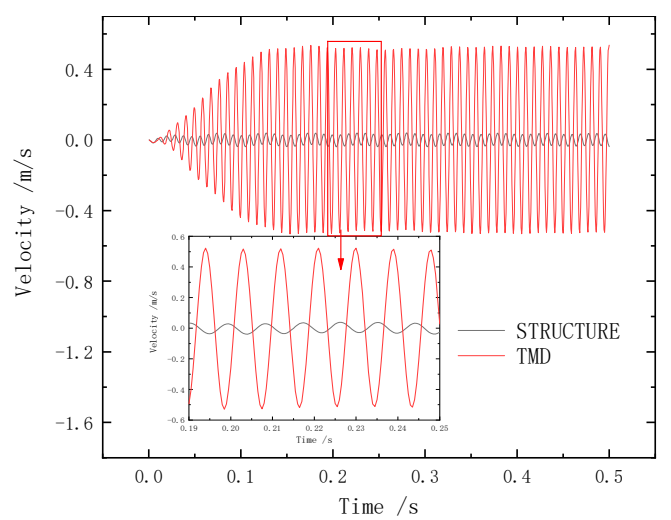

Figure 13. Comparison of structure and TMD velocity time-history curve. 
Figure 14 show the same rule as the test results. The layout at the bottom was better than that the top. As the number of controllers increased, the vibration reduction performance increased. Table 5 summarizes the velocity responses of different control strategy structures under harmonic load. Table 6 summarizes the results of the comparison between the test and the numerical acceleration response under the action of simple harmonic load. The correctness of the numerical calculation results was further verified by comparison with the experimental results. In the next section, the robustness of different control strategies was further studied through the frequency domain analysis.

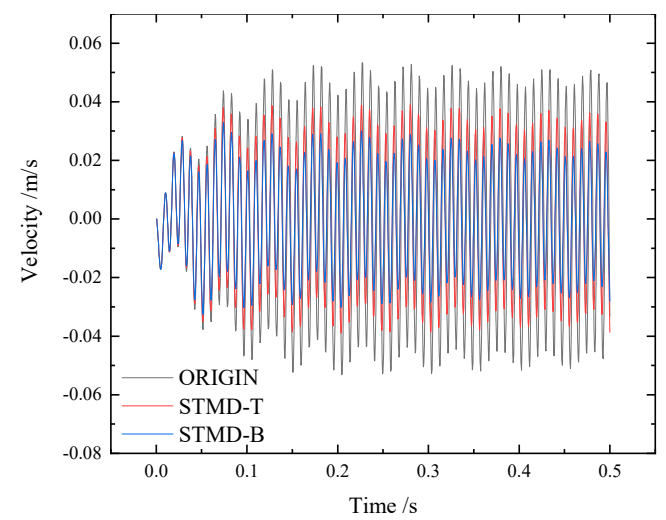

(a)

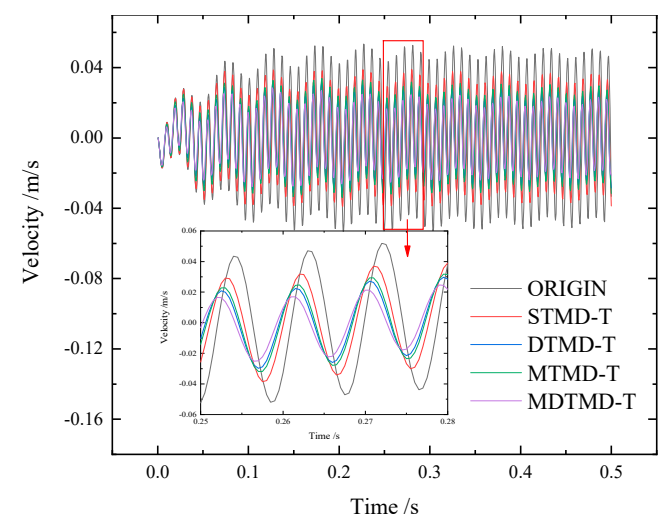

(b)

Figure 14. Velocity time history curves of structure under different TMD control strategies: (a) at different TMD positions of the same control strategy and (b) under different TMD control strategies.

Table 5. Peak velocity response of control strategies under simple harmonic load $\left(10^{-2} \mathrm{~m} / \mathrm{s}\right)$.

\begin{tabular}{cccccccc}
\hline Response & Original & TMD & STMD-T & STMD-B & DTMD-T & MTMD-T & MDTMD-T \\
\hline Velocity & 5.34 & 53.65 & 3.90 & 3.29 & 3.12 & 3.39 & 2.85 \\
\hline
\end{tabular}

Table 6. Comparison of experimental and numerical acceleration responses $(g)$.

\begin{tabular}{ccccc}
\hline \multirow{2}{*}{ Location } & \multicolumn{2}{c}{ Top } & \multicolumn{2}{c}{ Bottom } \\
\cline { 2 - 5 } & Experiment & Numerical & Experiment & Numerical \\
\hline Original & 3.52 & 3.52 & 3.80 & 3.99 \\
STMD-B & 1.83 & 1.71 & 1.91 & 1.92 \\
STMD-T & 2.47 & 2.47 & 2.87 & 2.8 \\
DTMD-B & 1.43 & 1.41 & 1.44 & 1.44 \\
DTMD-T & 1.95 & 1.92 & 2.40 & 2.30 \\
MTMD-B & 1.43 & 1.41 & 1.46 & 1.49 \\
MTMD-T & 2.38 & 2.07 & 2.69 & 2.42 \\
MDTMD-B & 0.79 & 0.9 & 0.80 & 1.14 \\
MDTMD-T & 1.37 & 1.39 & 1.68 & 1.62 \\
4MTMD-T & 1.33 & 1.29 & 1.40 & 1.38 \\
Spatial multi-point TMD & 0.95 & 0.95 & 1.03 & 1.2 \\
4MTMD-B & 0.81 & 0.88 & 1.00 & 0.96 \\
\hline
\end{tabular}

\subsection{Frequency Domain Analysis of TMD Installed on the Powerhouse Structure}

The frequency domain response curve reflects the amplitude information that corresponds to each frequency point after the fast Fourier transform has been applied to the vibration signal. It can more intuitively analyze the tuning of the TMD compared with the case without the TMD. The time domain analysis can only understand the structure's response change under a specific frequency excitation in the time domain, while spectrum analysis can not only understand the structure's amplitude at a specific frequency, but also analyze the amplitude change in different frequency ranges. Therefore, spectrum analysis can better understand the response changes of the vibration damping structure 
under different control strategies. This section uses a harmonic response analysis to analyze the spectral characteristics of the structure under different control strategies.

Figure 15a shows that the vibration amplitude of the top layer of the structure was greatly reduced due to the addition of the TMD device, indicating that the vibration damping performance of the structure with the additional TMD was better. Compared with the uncontrolled structure, the amplitude and response of the damping structure with the additional TMD under excitation frequency reached the minimum, which indicates that the parameter setting of the TMD was reasonable and effective. Since the parameters of the TMD did not change, it was observed that the control bandwidth was the same, while the vibration amplitude of the structure was small when the TMD was arranged at the bottom layer. This makes the bottom layer the maximum position of the vibration mode. As a result, the underlying TMD layout of the structure was more efficient and significant.

Figure 15b, c shows that as the number of TMD increased, the vibration reduction performance improved. More importantly, the width of the damper tuning band increased gradually, but the control effect decreased gradually in the whole band. In other words, multiple TMDs can increase the control bandwidth at the cost of loss control effect, but for a simple harmonic excitation load, multiple TMDs can still ensure the best control effect in the control band. For the four TMD control strategies in Figure $15 \mathrm{~d}$, all three cases show a good control effect, among which 4MTMT-B had a better control effect and robustness. When the external excitation is unstable, the robustness of multiple TMDs can ensure the vibration damping performance remains unchanged. If replaced by a single TMD, the unstable excitation may cause the controller to fail and, even further, increase the structural response. Therefore, multi-TMD coordination to improve robustness is particularly important in practical engineering.

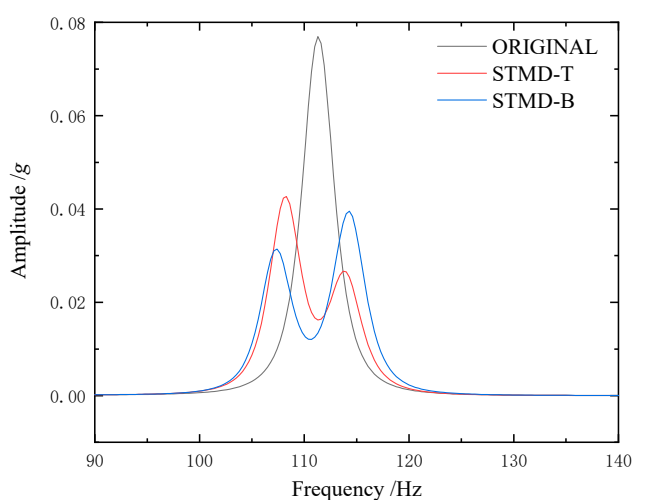

(a)

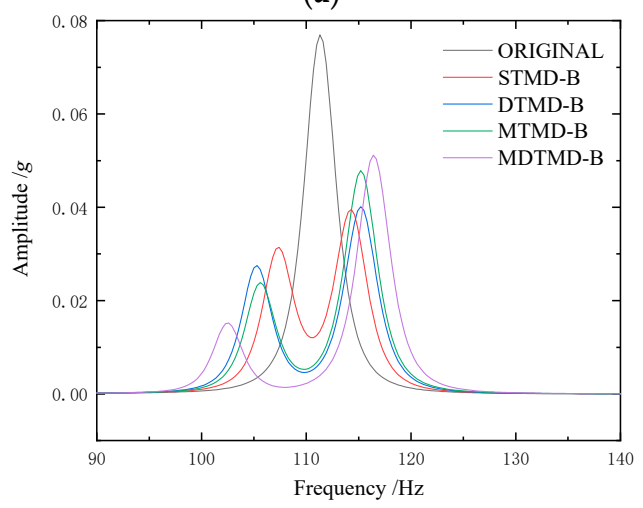

(c)

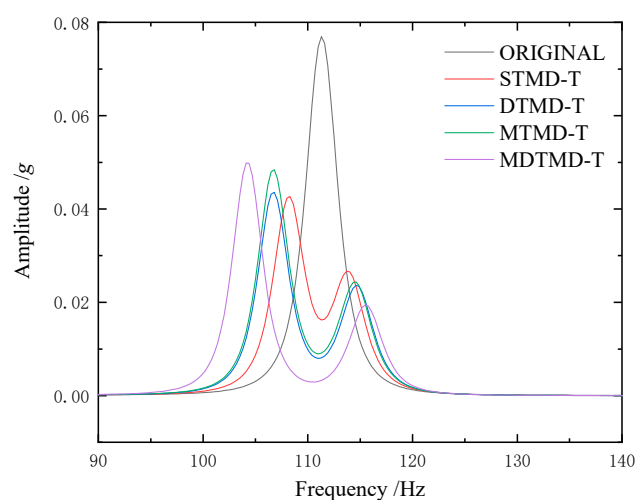

(b)

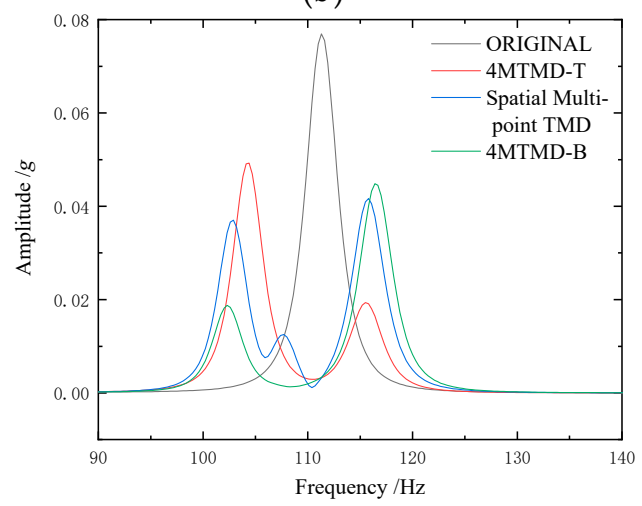

(d)

Figure 15. Frequency domain response curves of top layer of original structure and additional TMD damping structure: (a) STMD damping structure with different locations; (b) four cases of TMD placement on top of the structure; (c) four cases of TMD placement on the bottom of the structure; and (d) the quadruple TMD damping structure. 
In general, TMD design simplified to one degree of freedom has a good control effect on the high-frequency vibration of the powerhouse structure. On the one hand, the arrangement of multiple TMDs can improve the vibration control effect of the system, and on the other hand, it can increase the tuning frequency bandwidth of the TMDs, so the robustness is better. When using multiple TMDs in an MDOF structure, their optimal placement scheme is a concern. Further research should include the application of the proposed TMD method for other complex structures.

\section{Conclusions}

A novel methodology of a vibration control system for the high-frequency vibration of the superstructure of pumped storage power stations was proposed in this study. A spring plate was used to replace the spring elements of traditional tuned mass dampers to form a new TMD system that is suitable for high-frequency vibration control. The vibration problem of higher-order modes was simplified to a single mode vibration problem, and then the optimal design of a single-degree-of-freedom system was applied to the single-mode vibration to solve the high-frequency vibration problem of the structure. The feasibility of the proposed method was investigated by experimental and numerical simulations.

The experimental results show that compared with the uncontrolled structure, the time-history response of the plant structure using the TMD was significantly reduced, indicating that the TMD could effectively reduce the high-frequency vibration response of the structure. With the increased TMDs, the damping effect gradually increased, and the maximum RMSA attenuation rate reached $80.73 \%$. In addition, the control effect of the TMD at the bottom of the structure was better than that at the top layer. Numerical results verified the accuracy of the experiment. The TMD with non-optimal tuning parameters could not only reduce the high-frequency vibration of the structure effectively, but also amplified the vibration further due to its failure. In addition, the vibration velocity of the TMD system increased as it approached the tuning frequency ratio, so that the vibration absorption capacity reached the optimal level. As the number of TMDs increased, the damping effect increased and the tuning band of the TMDs gradually widened, showing good robustness and ensuring controller performance when the excitation was unstable.

From a practical perspective, passive structural control, especially using tuned mass dampers, is a robust, relatively inexpensive solution to reduce the risk of plant vibration in the PSPP environment. Using TMDs is a relatively new consideration for PSPPs, but in many civil engineering applications, the benefit of vibration reduction has been determined to be greater than the cost of TMDs. Therefore, although the feasibility of practical engineering application of PSPPs was not the focus of this paper, the significant vibration reduction demonstrated here highlights the potential for TMDs as an effective mechanism to reduce the vibrations of plant structures and improve the reliability of PSPPs.

Author Contributions: Conceptualization, T.Z. and X.F.; methodology, T.Z. and X.F.; software, T.Z.; validation, T.Z. and Y.Z.; formal analysis, T.Z.; investigation, T.Z.; resources, X.F. and J.Z.; data curation, X.F.; writing-original draft preparation, T.Z.; writing-review and editing, X.F.; visualization, T.Z.; supervision, X.F. and J.Z.; project administration, X.F. and J.Z.; funding acquisition, X.F. All authors have read and agreed to the published version of the manuscript.

Funding: This work was supported by the National Natural Science Foundation of China (grant no. 91215301).

Conflicts of Interest: The authors declare no conflict of interest.

\section{References}

1. Paish:, O. Micro-hydropower: Status and prospects. Proc. Inst. Mech. Eng. Part A J. Power Energy 2002, 216, 31-40. [CrossRef]

2. Spanhoff, B. Current status and future prospects of hydropower in Saxony (Germany) compared to trends in Germany, the European Union and the World. Renew. Sustain. Energy Rev. 2014, 30, 518-525. [CrossRef]

3. Perez-Sanchez, M.; Sanchez-Romero, F.J.; Ramos, H.M.; Lopez-Jimenez, P.A. Energy Recovery in Existing Water Networks: Towards Greater Sustainability. Water 2017, 9, 97. [CrossRef] 
4. Chu, S.; Majumdar, A. Opportunities and challenges for a sustainable energy future. Nature 2012, 488, 294-303. [CrossRef] [PubMed]

5. Amirante, R.; Cassone, E.; Distaso, E.; Tamburrano, P. Overview on recent developments in energy storage: Mechanical, electrochemical and hydrogen technologies. Energy Convers. Manag. 2017, 132, 372-387. [CrossRef]

6. Giosio, D.R.; Henderson, A.D.; Walker, J.M.; Brandner, P.A. Rapid Reserve Generation from a Francis Turbine for System Frequency Control. Energies 2017, 10, 496. [CrossRef]

7. Ohashi, H. Vibration and Oscillation of Hydraulic Machinery; Routledge: London, UK, 1991.

8. Tanaka, H. Vibration Behavior and Dynamic Stress of Runners of Very High Head Reversible Pump-turbines. Int. J. Fluid Mach. Syst. 2011, 4, 289-306. [CrossRef]

9. Shao, W.Y. Improving Stability by Misaligned Guide Ganes in Pumped Storage Plant. In Proceedings of the 2009 Asia-Pacific Power and Energy Engineering Conference, Wuhan, China, 28-31 March 2009; Volume 1-7, pp. 64-68.

10. Xu, W.; Xu, X.Y.; Ma, Z.Y. Analysis on vibration conductivity in walls of hydropower house based on power flow theory. Proc. Adv. Mater. Res. Trans. Tech. Publ. 2012, 424, 285-289. [CrossRef]

11. Wu, J.; Zhang, H.X.; Kou, Z.M.; Lu, C.Y. Numerical simulation on dynamic analysis for pipe vibration control based on an actively generated hydraulic excitation force. Proc. Adv. Mater. Res. Trans. Tech. Publ. 2012, 490, 2328-2332. [CrossRef]

12. Li, Y.; Li, Y. Analysis on the floor vibration of yantan hydroelectric generating station. J. Shenyang Agric. Univ. 2005, 36, 713-717.

13. Ma, Z.Y.; Shen, C.N.; Wang, Y.B. Studies on the Anti-vibration and Reinforcement of Powerhouse in Hongshi Hydropower Station. J. Hydroelectr. Eng. 2001, 1, 28-36.

14. Qian, Z.D.; Yang, J.D.; Huai, W.X. Numerical Simulation and Analysis of Pressure Pulsation in Francis Hydraulic Turbine with Air Admission. J. Hydrodyn. 2007, 19, 467-472. [CrossRef]

15. Spencer, B.; Sain, M. Controlling buildings-A new frontier in feedback. Shock Vib. Dig. 1998, 30, $267-281$. [CrossRef]

16. Soong, T.; Spencer, B. Supplemental energy dissipation: State-of-the-art and state-of-the practice. Eng. Struct. 2002, 24, 243-259. [CrossRef]

17. Singh, M.; Matheu, E. Active and semi-active control of structures under seismic excitation. Earthq. Eng. Struct. Dyn. 1997, 26, 193-213. [CrossRef]

18. Spencer, B.; Nagarajaiah, S. State of the art of structural control. J. Struct. Eng. 2003, 129, 845-856. [CrossRef]

19. Housner, G.W.; Bergman, L.A.; Caughey, T.K.; Chassiakos, A.G.; Claus, R.O.; Masri, S.F.; Skelton, R.E.; Soong, T.T.; Spencer, B.F.; Yao, J.T. Structural control: Past, present, and future. J. Eng. Mech. 1997, 123, 897-971. [CrossRef]

20. Kwok, K.C.S.; Samali, B. Performance of tuned mass dampers under wind loads. Eng. Struct. 1995, 17, 655-667. [CrossRef]

21. Pinkaew, T.; Lukkunaprasit, P.; Chatupote, P. Seismic effectiveness of tuned mass dampers for damage reduction of structures. Eng. Struct. 2003, 25, 39-46. [CrossRef]

22. Abe, M.; Fujino, Y. Dynamic Characterization of Multiple Tuned Mass Dampers and Some Design Formulas. Earthq. Eng. Struct. Dyn. 1994, 23, 813-835. [CrossRef]

23. Villaverde, R.; Koyama, L.A. Damped Resonant Appendages to Increase Inherent Damping in Buildings. Earthq. Eng. Struct. Dyn. 1993, 22, 491-507. [CrossRef]

24. Enriquez-Zarate, J.H.F.; Abundis-Fong, H.F.; Silva-Navarro, G. Passive vibration control in a building-like structure using a tuned-mass-damper and an autoparametric cantilever beam absorber. In Active and Passive Smart Structures and Integrated Systems 2015; International Society for Optics and Photonics: Washington, DC, USA, 2015; Volume 9431.

25. Li, C.X.; Zhu, B.L. Estimating double tuned mass dampers for structures under ground acceleration using a novel optimum criterion. J. Sound Vibr. 2006, 298, 280-297. [CrossRef]

26. Rana, R.; Soong, T. Parametric study and simplified design of tuned mass dampers. Eng. Struct. 1998, 20, 193-204. [CrossRef]

27. Ormondroyd, J.; Den Hartog, J.P. The theory of the dynamic vibration absorber. J. Appl. Mech. Trans. ASME 1928, 50, 9-22.

28. Hartog, J.D. Mechanical Vibrations; McGraw-Hill: New York, NY, USA, 1956. 
29. Soong, T.T.; Dargush, G.F. Passive energy dissipation systems in structural engineering. In Structural Engineering Handbook; Wiley: Hoboken, NJ, USA, 1997.

30. Netsch, H.; Giacometti, A. Axial flow-induced vibrations in large high-head machines. Int. Water Power Dam Constr. 1982, 34, 21-27.

31. Xu, W.; Ma, Z.Y. Study of the Vibration Transmission and Path Recognition of an Underground Powerhouse Using Energy Finite Element Method. Shock Vibr. 2016, 2016, 1-9. [CrossRef]

32. Zhi, B.P.; Ma, Z.Y. Path Transmissibility Analysis Considering Two Types of Correlations in Hydropower Stations. J. Appl. Math. 2013, 2013, 1-9. [CrossRef]

33. Thomson, W.T. Theory of Vibration with Applications; Prentice-Hall: Upper Saddle River, NJ, USA, 1972.

34. Li, J.W.; Gu, Z.F.; Zhu, H.F.; Yu, J.X.; Ouyang, J.H. Study on intense vibration of local structures of Zhanghewan pumped-storage powerhouse. In IOP Conference Series: Earth and Environmental Science; IOP Publishing: Bristol, UK, 2019; Volume 240, p. 082008.

35. Guo, L.; Rong, Q.; Ma, X.; Zhang, S. Behavior of steel plate shear wall connected to frame beams only. Int. J. Steel Struct. 2011, 11, 467-479. [CrossRef]

(C) 2020 by the authors. Licensee MDPI, Basel, Switzerland. This article is an open access article distributed under the terms and conditions of the Creative Commons Attribution (CC BY) license (http://creativecommons.org/licenses/by/4.0/). 